\title{
Prognostic value of the serum proteins during severe attacks of ulcerative colitis
}

\author{
F. T. de DOMBAL
}

From the Professorial Surgical Unit, The General Infirmary at Leeds

During the past two decades, several groups of workers have investigated the serum protein levels in patients suffering from ulcerative colitis (Tumen, Monaghan, and Jobb, 1947; Spellberg, Mosiman, and Smith, 1950; Bendandi, 1956; Bicks, Kirsner, and Palmer, 1959; Brooke, Dykes, and Walker, 1961 ; Soergel and Ingelfinger, 1961), and as a result of these investigations it is now widely accepted that changes in these protein levels sometimes occur. However, there is considerably less agreement about the precise nature of the changes which take place, and the mechanisms responsible, probably because most previous investigations have been confined to a single estimation of the serum proteins for each patient.

The present paper reports the serum protein levels which have been noted in a consecutive group of 46 patients suffering from severe attacks of ulcerative colitis. Serial electrophoretic studies have been performed in each instance, enabling the serum protein changes to be closely related to the clinical course of the patient.

\section{CLINICAL MATERIAL AND METHODS}

Between 1 January 1966 and 30 June 1967, 46 patients suffering from severe attacks of ulcerative colitis were admitted to hospital under the care of the Professorial Surgical Unit. Ulcerative colitis was diagnosed in each patient during life on the basis of characteristic symptoms, sigmoidoscopic appearances, and radiological studies. In each of the patients who came to surgery, the diagnosis was later substantiated by histopathological examination of the excised specimen. The mean age of the group of patients was 35.4 years, and the group was composed of 21 male and 25 female patients.

Each of the 46 patients was suffering from a severe attack of ulcerative colitis, defined according to the criteria laid down by Truelove and Witts (1955). All were ultimately discharged from hospital in good health, although radical surgery became necessary in 25 of the 46 patients.

Immediately upon admission a sample of $10 \mathrm{ml}$ of blood was removed from an arm vein for analysis. Further samples were collected at intervals of 24 to 48 hours, up to the time at which the patient either came to radical surgery or was discharged from hospital in remission; 478 blood samples in all were removed for analysis from the 46 patients.

The serum was separated immediately by centrifugation. Total proteins and total albumin levels were determined by means of a routine biuret reaction. Electrophoresis was performed usually within two or three hours of withdrawal of the blood sample, and in every case within 48 hours of withdrawal, the serum being stored frozen at a temperature of $-4^{\circ} \mathrm{C}$ in the intervening period. Electrophoresis was carried out in cellulose acetate membrane in a horizontal tank using a standard barbitone buffer of $p \mathrm{H} \mathrm{8.6}$. A constant current of 0.1 milliamps per centimetre strip was applied for a period of $75 / 90$ minutes. The strip was fixed in $5 \%$ trichloracetic acid and was stained in $1 \%$ light green.

The strip was then scanned, using an EEL scanner, Gaussian curves being used to divide the tracing into the appropriate fractions. The percentage of total protein occupied by each fraction was then evaluated in the usual way; and since the absolute values of the albumin and total globulin concentrations were known, the absolute concentration of each globulin fraction was simply determined.

There is as yet unfortunately no means of universal standardization of individual electrophoretic techniques. Samples were therefore initially removed from 20 healthy volunteers in order to determine the normal value and pattern for this particular technique and staining methods. These control samples were treated in exactly the same way as the samples from the patients with ulcerative colitis. Each specimen of serum was divided into two, and entirely separate investigations were performed on each of the two samples, the results being expressed as a mean of the two estimations. On rare occasions when these two estimations differed by more than $2 \%$ the results were discarded and a fresh sample was obtained.

\section{FINDINGS}

CONTROL SAMPLES The serum protein levels which were noted in the 20 healthy volunteers are shown in Table I. The concentration of each protein fraction is expressed in absolute terms as a mean value plus or minus one standard error. The values which were obtained by the particular technique outlined above differ little from those noted in healthy blood donors 
TABLE I

\begin{tabular}{|c|c|c|c|c|c|c|}
\hline \multirow{3}{*}{ Author } & \multicolumn{6}{|c|}{ ABSOLUTE SERUM PROTEIN LEVELS (IN $g \%$ ) IN NORMAL SUBJECTS } \\
\hline & \multirow{2}{*}{$\begin{array}{l}\text { No. of Cases } \\
\text { Studied }\end{array}$} & \multirow[t]{2}{*}{ Albumin } & \multicolumn{4}{|l|}{ Globulins } \\
\hline & & & Alpha 1 & Alpha 2 & Beta & Gamma \\
\hline $\begin{array}{l}\text { Kohn (1960) } \\
\text { Soergel and Ingelfinger (1961) } \\
\text { Present study (1967) }\end{array}$ & $\begin{array}{l}56 \\
24 \\
20\end{array}$ & $\begin{array}{l}4 \cdot 3 \\
4 \cdot 86 \pm 0 \cdot 73 \\
4 \cdot 54 \pm 0.68\end{array}$ & $\begin{array}{l}0 \cdot 2 \\
0 \cdot 49 \pm 0 \cdot 12 \\
0 \cdot 15 \pm 0 \cdot 02\end{array}$ & $\begin{array}{l}0.6 \\
0.58 \pm 0.13 \\
0.54 \pm 0.03\end{array}$ & $\begin{array}{l}0.7 \\
0.73 \pm 0.21 \\
0.69 \pm 0.03\end{array}$ & $\begin{array}{l}0.9 \\
1 \cdot 34 \pm 0.27^{1} \\
1 \cdot 03 \pm 0.05^{2}\end{array}$ \\
\hline
\end{tabular}

${ }^{1}$ Results expressed as mean \pm 1 standard deviation

2 Results expressed as mean \pm 1 standard error

by Kohn (1960) and by Soergel and Ingelfinger (1961).

COLITIC PATIENTS Studies were made on admission of the serum protein levels in all 46 patients, and the results of these initial estimations are shown in Table II. The principal findings were three, namely, a generalized fall in the serum albumin level in all 46 patients; a marked rise in the alpha 2 globulin fraction; and (in some patients) a fall in the serum gamma globulin level.

In trying to assess the prognostic value of these

TABLE II

ABSOLUTE SERUM PROTEIN LEVELS (IN g \%) IN PATIENTS WITH ULCERATIVE COLITIS

\begin{tabular}{|c|c|c|c|}
\hline \multirow{2}{*}{$\begin{array}{l}\text { Normals } \\
\text { (20) }\end{array}$} & \multirow{2}{*}{$\begin{array}{l}\text { Colitis in } \\
\text { Remission } \\
\text { (57) }\end{array}$} & \multicolumn{2}{|c|}{ Severe Attacks of Colitis } \\
\hline & & $\begin{array}{l}\text { Remission } \\
\text { (21) }\end{array}$ & $\begin{array}{l}\text { Surgery } \\
\text { (25) }\end{array}$ \\
\hline $\begin{array}{l}4.54 \pm 0.681 \\
0.15 \pm 0.02 \\
0.54 \pm 0.03 \\
0.69 \pm 0.03 \\
1.03 \pm 0.05\end{array}$ & $\begin{array}{l}4 \cdot 20 \pm 0 \cdot 15 \\
0 \cdot 15 \pm 0 \cdot 02 \\
0 \cdot 69 \pm 0.03 \\
0 \cdot 74 \pm 0 \cdot 03 \\
1 \cdot 14 \pm 0.07\end{array}$ & $\begin{array}{l}3 \cdot 34 \pm 0.24 \\
0.26 \pm 0.03 \\
0 \cdot 86 \pm 0.06 \\
0 \cdot 80 \pm 0.04 \\
1 \cdot 12 \pm 0.08\end{array}$ & $\begin{array}{l}2.97 \pm 0.19 \\
0.26 \pm 0.03 \\
0.84 \pm 0.06 \\
0.66 \pm 0.05 \\
0.82 \pm 0.09\end{array}$ \\
\hline
\end{tabular}

1 Results expressed as arithmetic mean \pm 1 standard error.
Figures in parentheses indicate numbers of patients analysed in each category. serum protein changes in severe attacks, several difficulties were at once apparent. Thus although the serum albumin level on admission was generally low, this unfortunately applied to all patients whether they got better upon conservative management or not, and hence from a prognostic point of view serum albumin level studies were useless. Similarly the alpha 2 globulin fraction was much raised in all 46 patients, whether or not they responded to conservative measures, and so clearly this fraction cannot be used for prognosis either.

However, it is noticeable from Table II that the gamma globulins were slightly raised on admission in the group of patients who responded to conservative management, whereas in the patients who did not so respond (all of whom subsequently came to surgery) the gamma globulins on admission were generally below the normal range. It seemed then that any attempt to base a prognosis upon the serum protein levels in severe attacks of ulcerative colitis should take special account of the gamma globulin level. This level was therefore assessed throughout the course of each severe attack by means of serial studies and the results of these studies are shown in Figure 1.

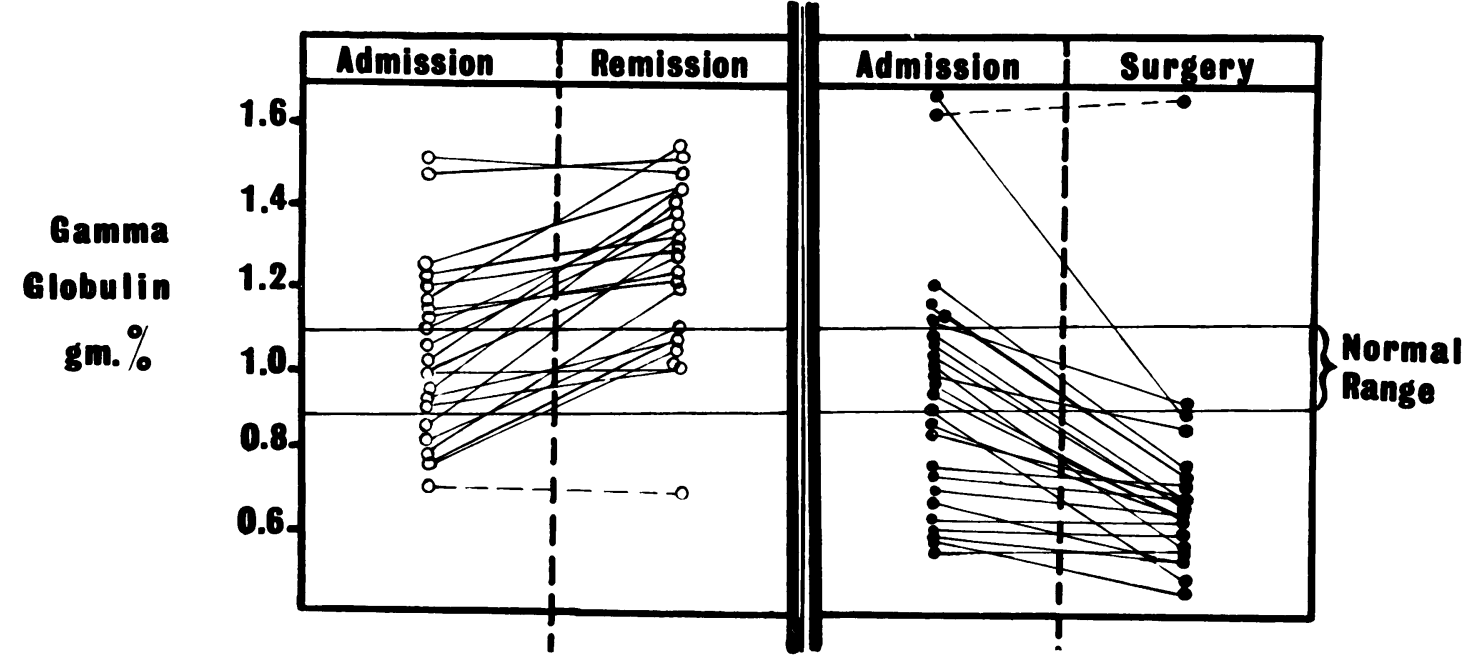

FIG. 1. Serial gamma globulin levels throughout 46 severe attacks of ulcerative colitis. 


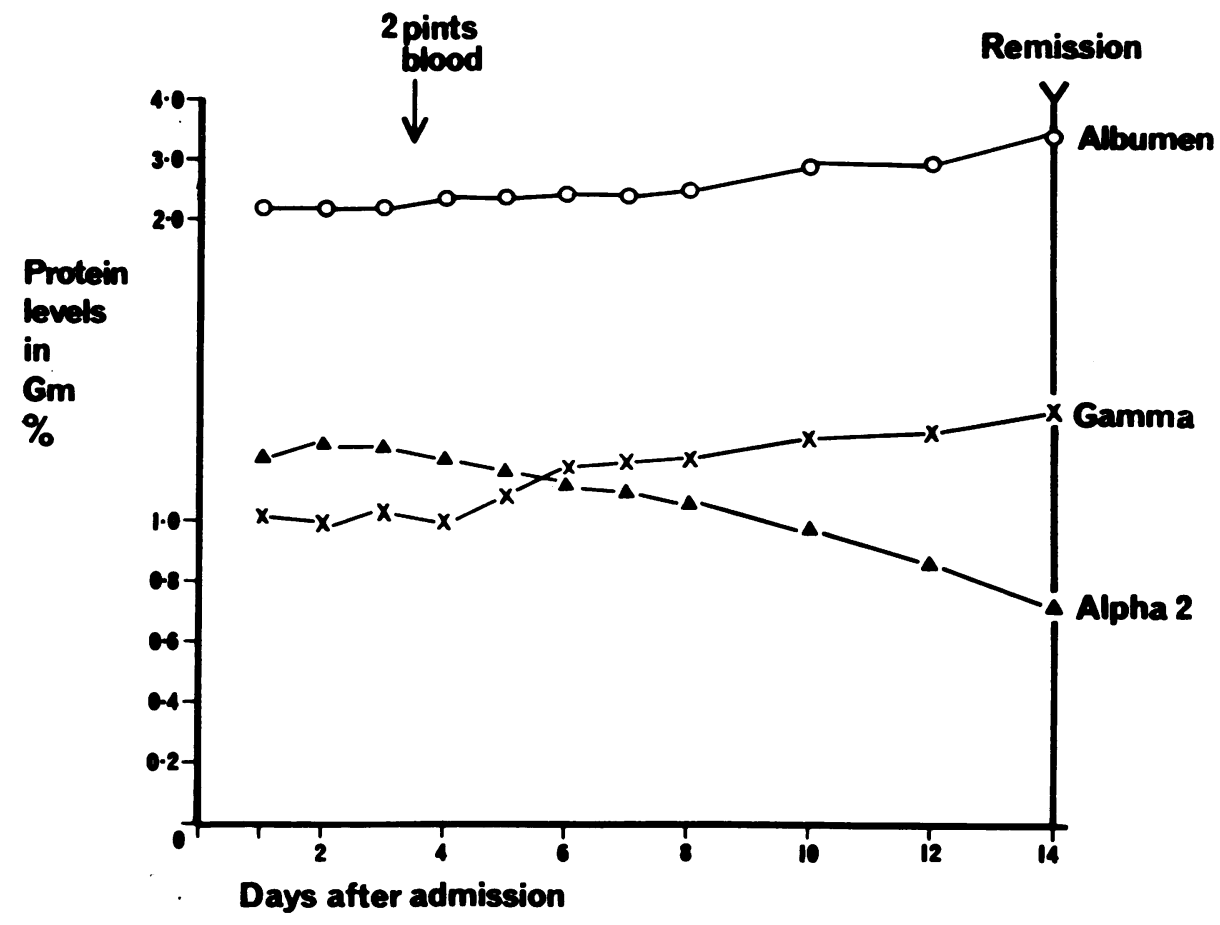

FIG. 2. Serum protein levels observed during $a$ severe attack in a woman aged 26 treated with steroids and salazopyrine. Clinical

improvement first noted on eighth to ninth day after admission. Rise in gamma globulin precedes clinical improvement by approximately four days.

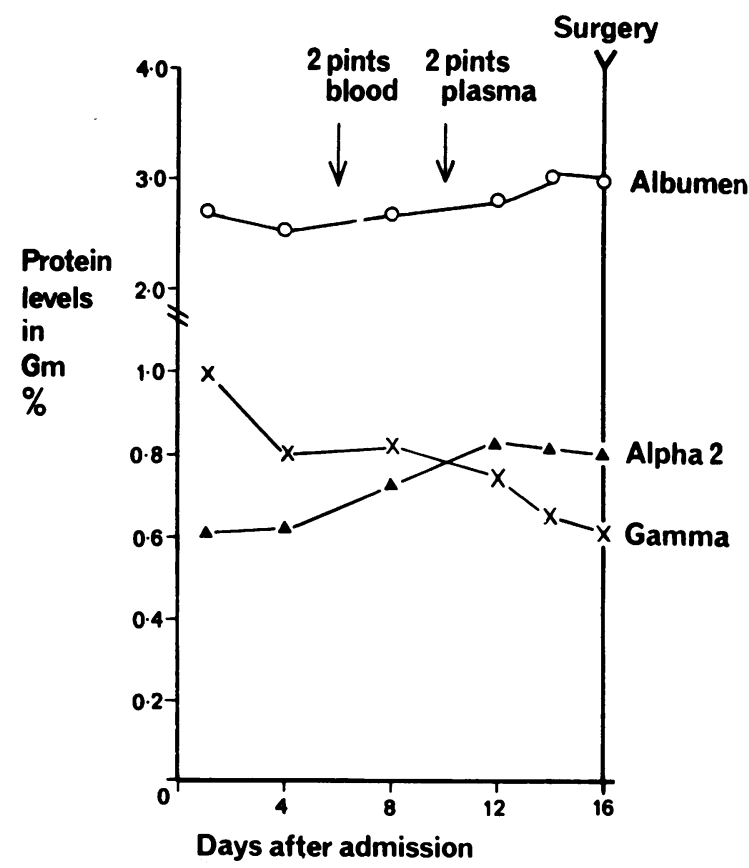

FIG. 3. Serum protein levels during a severe attack in a woman aged 46. Some clinical improvement on steroids and salazopyrine maintained up to thirteenth day after admission, with subsequent deterioration and need for urgent surgery. Fall in gamma globulin precedes clinical deterioration by approximately one week. 
Of the 21 patients who responded to conservative management, no fewer than 20 had a high or rising gamma globulin during the course of their severe attack, and all but two had a gamma globulin level well above normal at the time of their discharge in remission. In complete contrast, of the 25 patients who ultimately came to surgery, all but one had a low or falling gamma globulin level throughout the course of their severe attack.

Two further points need emphasis. First, the decision to bring these patients to surgery was taken entirely on clinical grounds by other members of the Professorial Surgical Unit, who were themselves entirely unaware of the biochemical findings in the present study. Second, it must be emphasized that the progress of each individual patient's gamma globulin level approximated (with minor fluctuations only) to the straight lines which have been drawn for the sake of clarity in Figure 1. This point can be emphasized by a glance at the protein levels in two typical individual patients (Figs. 2 and 3).

Thus the results of this study suggest that if in a severe attack of ulcerative colitis the gamma globulins are high or are rising throughout the course of the attack, then the outlook for that individual patient is excellent. If, by contrast, the gamma globulin level is low or falling, then the outlook for that patient is bleak because such patients almost invariably fail to respond to conservative measures and ultimately will require radical surgery.

IMMUNOPHORESIS Qualitative immunophoretic studies were carried out on a number of patients. The findings indicated that patients exhibiting a raised alpha 2 globulin level showed a fairly nonspecific rise of all the various alpha 2 globulin fractions-perhaps the most spectacular rise being in the haptoglobulins. Patients with an overall rise in the gamma globulin fraction also showed a nonspecific pattern on qualitative immunophoresis, with marked increases in the IgM, IgG, and IgA fractions. Clearly, therefore, the important problem raised by the present study, namely, which of the various alpha 2 and gamma subfractions are rising and falling, can only be answered by quantitative immunophoretic studies.

It is unfortunate that at the time of the present study quantitative immunophoresis was not feasible. However, recent encouraging progress has been made in this direction (Clarke and Freeman, 1966); and further quantitative immunophoretic studies are now in progress (de Dombal and Allen, 1968).

DISCUSSION

Recently there has been considerable interest in the clinical course and prognosis of patients suffering from ulcerative colitis (Edwards and Truelove, 1963; Watts, de Dombal, Watkinson, and Goligher, 1966 $a, b)$. These two major surveys (which together analysed the course and prognosis of ulcerative colitis in over 1,000 patients) were able to define in statistical terms the course and outcome of the disease with some precision in the large groups of patients studied. But it must be stressed that any such prognosis derived from using large groups of patients is of limited value only when the problems of the individual patient are considered, and what is now required, in addition to such large scale surveys, is a means of predicting the course and outcome of ulcerative colitis in the individual patient. The present paper proposes just such a method based upon simple electrophoresis of the serum proteins.

The relationship between ulcerative colitis and the serum proteins has stimulated considerable interest in investigations in this field also. Indeed, it is now nearly 20 years since Tumen et al. (1948) and Spellberg et al. (1950) demonstrated changes in the serum protein levels in colitic patients; and since then many workers have investigated the detailed nature of these changes. Bicks et al. (1959) studied 63 patients with ulcerative colitis, no fewer than 61 of whom showed a low albumin level, together with a rise in the alpha 2 globulin fraction; and in 45 of these 61 patients the gamma globulin concentration was also raised. However, the protein concentrations were expressed in this survey as percentages of total (unknown) protein levels, rather than in absolute terms, and thus it was difficult to know whether the values obtained by Bicks and his colleagues represented relative or absolute changes. Further, although 'serial' studies were in fact performed, the interval between the withdrawal of samples from each patient apparently varied between one week and six months, and finally, Bicks and his colleagues unfortunately omitted to define the criteria which were used to describe the clinical progress of the patient's colitis.

Brooke et al. (1961) confirmed that a rise in the alpha 2 globulin fraction occurs in patients with ulcerative colitis. However, since these workers again expressed their results in the same way as Bicks and his colleagues, they were unable to say whether the rise in the alpha 2 globulin fraction was absolute or relative; and they suggested that the alpha 2 rise was in fact relative, and due to a selective leak of proteins of smaller molecular weight. Soergel and Ingelfinger (1961) expressed their results in absolute terms, and found that in 20 patients severely ill with ulcerative colitis there was a low serum albumin level and an absolute rise in the alpha 2 globulin concentration. However, once again workers failed 
to define their clinical criteria, and omitted to perform serial studies on individual patients.

In analysing the data provided in the present study, two points are immediately apparent. First, it is clear that the electrophoretic pattern of the serum proteins is far from static in patients with severe active ulcerative colitis, and is constantly changing along with their clinical status. This feature emphasizes the need for serial studies of such patients, and indeed a glance at Figs. 1, 2, and 3 shows the extreme difficulties which may be encountered if a group of such patients are investigated by means of a single estimation.

Moreover the complex nature of the observed changes emphasizes the need for expression of the results in absolute rather than relative terms. It has been argued (Jencks, Jetton, and Durrum, 1955; Bicks, 1961), that the presentation of results in absolute terms means that such results cannot be expressed with as high a degree of accuracy as results expressed in percentage terms alone. But in practice the unavoidable error of estimation using this technique is small, being of the order of $\pm 0.03 \mathrm{~g} \%$ for the gamma globulin fraction (de Dombal, 1967). A further glance at Figs. 1, 2, and 3 shows that this error of estimation $( \pm 0.03 \mathrm{~g} \%)$ cannot possibly be of any significance in dealing with changes of the magnitude shown.

The most interesting finding in the present study has been the behaviour of the gamma globulins. It is fascinating to record that surgery ultimately became necessary in all but one of the 25 patients found to have a low or falling gamma globulin concentration. By contrast, almost every patient with a high or rising gamma globulin level subsequently went into remission on conservative management alone.

Two aspects of these findings concerning the gamma globulins are of interest. The first aspect deals with the currently fashionable hypothesis that there may be some underlying autoimmune basis for the pathogenesis of ulcerative colitis, for in this context it is surely of interest that a rise in the various gamma globulin antibody fractions seems to confer a good prognosis upon the individual patient. The second aspect of these findings is of more immediate practical significance, for it deals with the possibility that serial electrophoretic studies may be of some use in the day-to-day clinical management of patients suffering from severe ulcerative colitis.

The difficulties in the clinical assessment of a severely ill colitic patient, who is usually on corticosteroid therapy, are well recorded (Brooke, 1956; Goligher, 1967; de Dombal, Watts, Watkinson, and Goligher, 1965; Graham, de Dombal, Watkinson, and Goligher, 1967), and it may be mentioned in passing that the present series of patients was no exception in this respect. It seems, therefore, that serial studies of the patients' serum protein levels may sometimes be of considerable practical value in this situation; for, in some patients, serial protein studies may well provide a more accurate reflection of the course of their disease than that provided by clinical evaluation alone. Moreover, changes in the serum protein levels may often precede the corresponding changes in the clinical picture-sometimes by a matter of days.

Clearly this is not to say that such biochemical studies should entirely replace clinical evaluation. It has already been repeatedly emphasized that the colitic patient whose clinical condition deteriorates on medical treatment (or fails to improve within a specified time) should come to surgery; whereas, in complete contrast, some patients improve so rapidly on conservative management that the question of surgery never arises (Goligher, de Dombal, Graham, and Watkinson, 1967). The fact that these patients almost invariably show corresponding changes in their gamma globulin level is irrelevant in terms of their clinical management.

Nevertheless, patients who do well on conservative measures must be differentiated from yet another group of patients who apparently improve for a period of some days or even weeks, only for the colitis to relapse again with renewed virulence. It is in distinguishing between these groups of patients that serial determinations of the serum proteins may be of value, for their subsequent fate seems to be closely related to the level of the serum gamma globulin.

It is therefore suggested that serial studies of the electrophoretic patterns of the serum proteins may be a useful adjunct to the clinical evaluation of many patients with severe attacks of ulcerative colitis. In particular, the patient who appears to improve upon conservative management, yet maintains a low or falling gamma globulin concentration, should be treated with extreme caution, for in view of the present findings, it seems highly probable that the apparent improvement in the patient's general health may well be only a temporary phenomenon.

\section{SUMMARY}

Forty-six patients suffering from severe attacks of ulcerative colitis have been investigated by means of serial electrophoretic studies of their serum proteins. Four hundred and seventy-eight serum protein estimations were carried out in these patients.

All patients with severe ulcerative colitis showed a decrease in the serum albumin level, and all showed 
a marked increase in the alpha globulin fractions. These changes were absolute and not merely relative.

The gamma globulin concentration varied widely from patient to patient. Patients with a high or rising gamma globulin concentration survived their acute, severe attack on conservative management alone. All but one of the patients whose gamma globulin concentration was low or falling came to urgent or emergency surgery, because conservative management failed to control the attack of colitis.

The difficulties encountered in the clinical evaluation of patients with severe ulcerative colitis are well known. It is suggested that serial estimations of the serum proteins, and in particular of the gamma globulins, may be a useful adjunct to the clinical evaluation of such patients.

I am grateful to Professor J. C. Goligher for his advice and encouragement, and for permission to study patients under his care. I am also indebted to Mrs. R. Bulmer for her technical assistance, and to Dr. R. B. Payne for the qualitative immunophoretic studies on some of these patients.

\section{REFERENCES}

Bendandi, S. (1956). Liver function in ulcerative colitis. Gastroenterologia (Basel), 86, 658-666.

Bicks, R. O. (1961). In discussion to Soergel and Ingelfinger. Gastroenterology, 40, 45-46.

—, Kirsner, J. B., and Palmer, W. L. (1959). Serum proteins in ulcerative colitis. Electrophoretic patterns in active disease. Gastroenterology, 37, 256-262.

Brooke, B. N. (1956). The outcome of surgery for ulcerative colitis. Lancet, 2, 532-536.
-, Dykes, P. W., and Walker, F. C. (1961). A study of liver disorder in ulcerative colitis. Postgrad. med. J., 37, 245-251.

Clarke, H. G. M., and Freeman, T. (1966). A quantitative immunoelectrophoresis method (Laurell electrophoresis). Protides of the Biological Fluids, vol. 14, pp. 503-509. Elsevier, Amsterdam.

de Dombal, F. T. (1967). Serum proteins in ulcerative colitis: electrophoretic patterns in the inferior mesenteric artery and vein. Gut, 8, 482-485.

in ulcerative colitis. In preparation.

—, Watts, J. McK., Watkinson, G., and Goligher, J. C. (1965). Intraperitoneal perforation of the colon in ulcerative colitis. Proc. roy. Soc. Med., 58, 713-715.

Edwards, F. C., and Truelove, S. C. (1963). The course and prognosis of ulcerative colitis. Gut, 4, 299-315.

Goligher, J. C. (1967). Surgery of the Anus, Rectum and Colon, 2nd ed. Bailliere, Tindall and Cassell, London.

-, de Dombal, F. T., Graham, N. G., and Watkinson, G. (1967). Early surgery in the management of severe ulcerative colitis. Brit. med. J., 2, 193-195.

Graham, N. G., de Dombal, F. T., Watkinson, G., and Goligher, J. C. (1967). The management of the acutely ill colitic patient. In preparation.

Jencks, W. P., Jetton, M. R., and Durrum, E. L. (1955). Paper electrophoresis as a quantitative method; serum proteins. Biochem.J., 60, 205-215.

Kohn, J. (1960). C'hromatographic and Electrophoretic Techniques, vol. II. Zone Electrophoresis, p. 74. Heinemann, London.

Soergel, K. H., and Ingelfinger, F. J. (1961). Proteins in serum and rectal mucus of patients with ulcerative colitis. Gastroentero$\log y, 40,37-46$.

Spellberg, M. A., Mosiman, W. D., and Smith, L. C. (1950). Electrophoretic studies of plasma proteins in ulcerative colitis. (abstr.). J. Lab. clin. Med., 36, 991.

Truelove, S. C., and Witts, L. J. (1955). Cortisone in ulcerative colitis. Brit. med. J., 2, 1041-1048.

Tumen, H. J., Monaghan, J. F., and Jobb, E. (1947). Hepatic cirrhosis as a complication of chronic ulcerative colitis. Ann. intern. Med., 26, 542-553.

Watts, J. McK., de Dombal, F. T., Watkinson, G., and Goligher, J. C. (1966a). The early course of ulcerative colitis. Gut, 7, 16-31. colitis. Brit. med. J., 1, 1447-1453. 